\title{
A simple, affordable, scaled-up way of creating materials for personalized learning with educational technology: Crowdsourcing Open Educational Resources
}

When education moves online, that creates a need for new learning materials that are available online, can be broadly disseminated via the internet, can be displayed to and used by learners on technological devices such as computers, smartphones, or tablets, are up-todate, affordable and available for public schools, in line with schools' curricula, and matching the individual needs of the learners and their educators.

Three trends have made such technology-compatible, up-to-date, high-quality learning materials tailored to individual students' needs wanted at large scale: The pandemic-induced home schooling, the generally increasing importance of learning with educational technology, and the trend towards personalized learning.

While the educational technology infrastructure is being developed at scale, the experiences during the COVID-19 pandemic have revealed that the development of learning materials for online learning lags behind. This article proposes a simple solution to all of these problems:

Systematic crowdsourced creation of open educational resources.

by Julia Moeller

\section{The problem: An urgent need for technology-compatible learning materials that are up- to-date, of high quality, tailored to students' individual needs, in line with schools' curricula, and secure}

When the COVID-19 pandemic hit, many educators, schools, and educational policy makers struggled to provide students with suitable instructions and learning materials to continue their education remotely from their homes. Some students reported receiving little to no instruction, sometimes not hearing anything at all from teachers for weeks at a time. Some students and parents reported feeling left alone with only pdf-worksheets to work with, containing generic tasks that some students found over- and others underwhelming. Teachers around the world reportedly struggled with the tasks of taking their materials online. Having to produce learning materials for remote education brought new challenges for many teachers, ranging from the question of how to create, layout, and edit learning materials on computers, to the problem that many teachers are not even equipped with the required soft- and hardware needed for such editing processes. On top of that came concerns about copyright, because existing textbooks cannot simply be copied to be distributed online by a teacher, as well as data protection concerns. The problems were so staggering that some educational policy makers took the task of producing learning materials out of the teachers' hands -and out of the public sector- and instead decided to rent the access to computerized learning materials at large scale from private for-profit publishers. While this may have brought some temporary relief to public schools in some areas, it may not be a sustainable and desirable long-term solution.

The need for high-quality technology-compatible learning materials will persevere, not only because of the difficult months ahead of us that is expected to bring sky-rocketing infection rates among often unvaccinated school children with the foreseeable need of quarantines and home-schooling for many students. If and when this pandemic finally ebbs away, we can expect to see perseverant efforts to include learning with educational technology into the practices and curricula of schools worldwide. Such learning with educational technology is likely to be more personalized, meaning more tailored to individual students' learning needs, than ever before. All of these educational trends and necessities 
indicate that there will be a perseverant need for learning materials that are compatible with personalized learning with educational technology. More precisely, what schools need are large pools of learning tasks and materials that cover a wide range of individual learning needs and are diversified in terms of difficulty level, to provide the right task for the right student at the right time. The learning materials need to be tailored to schools' current curricula and local preferences, rules, and regulations. They need to fit to individual teachers' learning strategies as much as to their students' individual needs. The materials need to be available at scale, widely affordable to public schools, and ideally enable teachers to disseminate the materials to all of their students without having to worry about copyright infringements. The learning materials should have layout and structure compatible with computer displays large and small, for instance to enable bring-your-own-device-approaches and to be compatible with the large variety of devices potentially available at schools. Furthermore, the involvement of educational technology and personalization raises new and crucial concerns about data protection, privacy, and information security, which has turned out to be overwhelming for many of the teachers, parents, educational policy makers and even software developers at the moment. Ideally, individual teachers may want to maintain the traditional option of creating their own learning materials and ideally, the need to computerize these tasks should not make this goal unattainable for instance due to worries about lacking computer skills, lacking knowledge about data protection, or concerns about copyright protection. If regulations, curricula, or the state of the world changes in some way, as it tends to do, the learning materials need to be updated quickly and teachers and policy makers in different schools or regions may want to implement these changes as independently and flexibly as possible. Maybe public policy makers and taxpayers want to hold on to the tradition of having learning materials for public schools being developed by teachers paid by the public school system, instead of making teaching practices too dependent on private forprofit companies whose monetary and copyright interests, limited variety of offered materials and privacy practices may be misaligned with the needs and interests at play in the public education sector.

\section{The solution: Systematic crowdsourced creation of open educational resources}

Fortunately, there is a solution that, if well done, can be simple, affordable, secure, flexible, personalized, at scale, easy to update and agreeable with the needs of the public schooling systems worldwide: By combining the instruments of crowdsourcing with Open Educational Resources in a collaboration between teachers, teacher students, university educators of teacher students, technology experts, educational policy makers and philantropists.

\section{Open educational resources (OER)}

Open educational resources are learning materials that are openly available on the internet. Everyone can download, use, share and change them because their use, reproduction and dissemination are not limited by copyright. Anyone can create open educational resources and share them with the world by uploading them to the internet. Educators and learners looking for open educational resources can find them in curated online repositories where professional moderators select and highlight open educational resources that meet certain quality standards. There are initiatives of educators writing entire textbooks as open educational resources. Numerous websites offer tutorials and software teaching anyone interested in open educational resources how to create, layout, share, and use them. In some countries, including Germany, publicly funded OER repositories and information about OER are already part of the technological education landscape.

Imagine the possibilities if we could channel the brainpower of educators into creating and using open educational resources more systematically! 


\section{Crowdsourcing}

Everyday thousands of teachers and teacher students develop new learning materials on their computers in the context of their teaching preparation or their teacher studies. Imagine the treasure of learning materials developing like that every day, week, month! How easy would it be to curate a large pool of learning materials for all classes, subjects, school types, and difficulty levels if only we found a way to collect these learning materials that are being developed all the time anyways and to give all schools access to this learning material collection. It would be a game-changer if only we found a way to make sure that at least a certain percentage of the teachers who currently develop learning materials for their own classroom systematically shared them as open educational resources with the public.

This way, active teachers and teacher students could create large pools of professional learning materials to be used on computers and disseminated via the internet without investing much more time and effort than they are currently investing already every day.

Universities and institutes involved in teacher education, meaning the formation of new teachers, could contribute to this pool by making sure that the many learning materials that teachers-to-be create as part of their studies are also shared as open educational resources. Since the learning materials developed by teacher students are typically evaluated by their teachers, it should be easy to incorporate quality control standards making sure that only those materials deemed useful by the university teachers are added to the overall pool. University educators of teacher students could further contribute to making this plan work by: instructing and supervising the creation of OER in the seminars and exercises of teacher studies, by training active teachers in how to develop OERs in workshops, by evaluating existing OERs in student projects and seminars, by creating concepts for quality control in regard to OERs, by serving on scientific board for this campaign and by supervising internships of teachers developing their OER skills in the context of the here proposed crowdsourced OER campaign. In the long run, researchers could help develop valid, reliable, objective computerized instruments to assess and predict individual learning needs and matching interventions, not only in regard to the cognitive knowledge about specific school subjects, but also individual learning needs in regard to in regard to emotional and motivational support, self-regulation, and ICT skills (information and communications technology skills, such as how to use computers, the internet, and different software applications). To match the open education idea, such instruments of individualized diagnostics and interventions should ideally be freely available and compatible with the computer infrastructure available in schools. Another longterm contribution of researchers to this campaign could be the development and evaluation of evaluate educational concepts how learning and teaching with computers in personalized settings can and should work. This would help to fill the gap that currently many resources are being dedicated to developing new technological solutions, while there is still a need to develop visions and strategies helping teachers and students navigate the use of these new technologies. Ideally, such teaching-learning concepts should be informed by interdisciplinary research on learning with educational technology.

Technology experts could contribute to this developing pool of learning materials by hosting and maintaining the publicly available learning management systems (LMS) meeting the needs of the public school system (for examples, see e.g., Moodle in the federal states of Saxony-Anhalt and Baden-Württemberg, Lernsax, Thüringer Schulcloud). In addition to hosting the learning environment where teachers and students meet and exchange learning materials and completed tasks, technology experts are needed for the hosting, maintaining and further developing of the open educational resources repositories, where teachers can up- and download open educational resources, and where ideally such open educational resources can be filtered by certain quality control indicators and key words, such as school types, school subjects, specific learning topics, and difficulty levels. In countries where both publicly 
available learning management systems and repositories for open educational resources already exist, a next task for technology experts could be to facilitate the systematic use of open educational resources in such learning management systems by creating links or integrations between both types of online environments, for instance by enabling teachers setting up a course in a learning management system to select open educational resources within this environment, like in the case of a Biology teacher, who sets up their course for the current term in the learning management system used by their school and can select within this learning management system all the Biology learning materials previously used by other teachers within the same school, school district, or country. For an example of OER integrated in learning management systems, please see the LernStore in the dBildungsCloud. Another important contribution of technology experts could be a further development of quality control mechanisms in OER repositories. Currently, some repositories are curated so that only those materials that have been vetted by educational experts appear there. However, this centralized quality control may not be able to keep up with the amount of uploads and with the demand that would occur if the systematic crowdsourced creation of open educational resources took place at scale. For instance, in the future, OER repositories could include rating systems allowing users to rate the quality, correctness, difficulty level and usefulness of uploaded OER materials, as well as analytics pointing out links between uploaded materials as in saying "users who downloaded this learning task also downloaded that other learning task". Technology experts could develop and implement such quality control mechanism compatible with the crowdsourcing idea requiring many OER materials being rated by many users. Further tasks for technology experts would be to ensure privacy, data protection and information security in the OER repositories and publicly used learning management systems. In addition, input from technology experts is needed when training teachers in how to develop and use OER repositories.

Educational policy makers, including those working at ministries of education, school boards and other political institutions could help initiating this crowdsourcing OER campaign by declaring it a political goal. Furthermore, educational policy makers could provide essential support by providing some funding for coordinators and for the technology experts as well as patronage for the campaign initializing the broad use and creation of OER materials by a large number of teachers.

Similar support could additionally come from foundations and other donors, whose support would help to initiate and fund the campaign and to bring it to the spotlight of attention through patronages and public relations/media work.

The following figure illustrated the interplay of these actors in making this campaign of the crowdsourced creation of OER learning materials happen: 


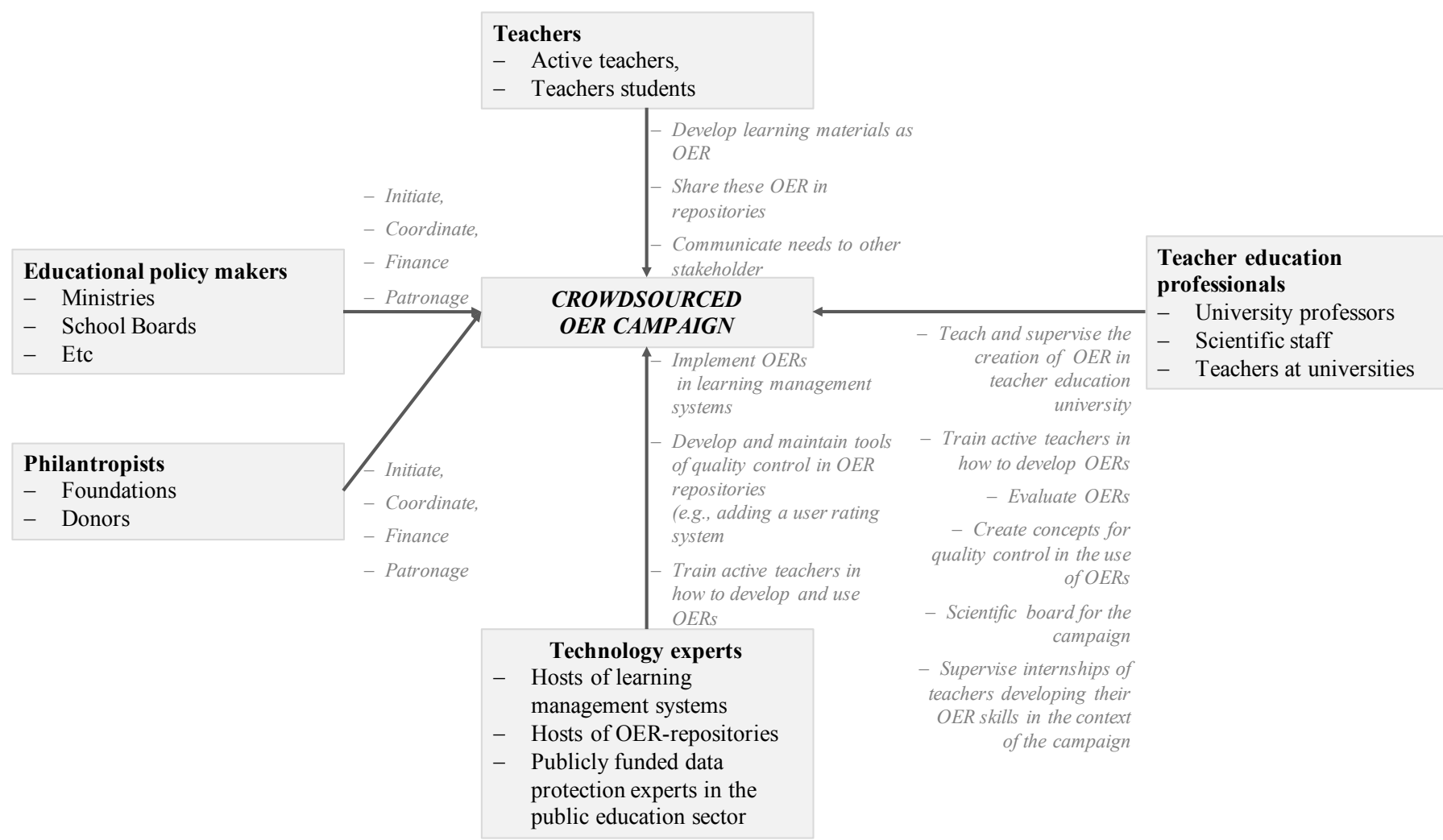

Figure 1. Campaign for the systematic crowdsourced creation of open educational resources for public schools

\section{Advantages of the crowdsourced OER campaign}

The advantages of this here proposed campaign of creating OER learning materials suing crowdsourcing are:

1. The public school system would win a large pool of up-to-date learning materials suited for diverse school types, school subjects, and difficulty levels.

2. The already existing resources, products and competences of existing protagonists of the public education system (e.g., teachers, teacher education institutions, hosts of publicly funded learning management systems and OER repositories) are used more efficiently and more sustainably.

3. The pools of learning materials produced for the computer-based and/or remote and/or personalized learning created through this crowdsourced campaign are likely to be larger, more differentiated, more in line with individual schools' and teachers' needs, cheaper, and available for longer time spans and to broader audiences than the typically available learning materials offered by private publishers

4. The interdisciplinary collaboration among the various actors on the public education system is strengthened in the long run.

5. The learning materials remain available to the broader public, including after the pandemic. They can be used not only to get through times of home schooling and school closures, but afterwards serve for teaching and learning with educational technology (called "digital education" in Germany). The diversity of OER materials of all difficulty levels prepares the move towards more personalized learning in the public education system, which needs learning materials of different difficulty levels to provide the right task to the right student at the right time.

6. The competences of teachers and teacher students in creating learning materials for teaching with computers and educational technology are fostered.

7. The transfer from research to applied learning settings and back is fostered. 
8. In the long run, we can expect a substantial improvement of the cost-value ratio and the return on investment, if public funding is used to pay for the coordinated work with publicly available learning materials, compared to the previous practice of having to buy or rent copyrighted materials from private publishers.

9. The content control of available learning materials remains in the hands of publicly funded actors of the public education system.

10. The ability to control privacy and information security stays in the hands of publicly funded experts.

\section{What is needed for implementing this solution? The example of Germany}

In Germany, where both publicly funded learning management systems and OER repositories exist, the next steps towards making such a campaign happen would require getting educational policy makers and funders on board, who can initiate, advertise, and patronage a larger awareness campaign. Their media teams could help raising the awareness for this idea all over the country. Centrally organized hackathons could serve as kick-off events for the campaign. Smaller interdisciplinary teams of coordinators and multipliers could be formed to serve as liaisons between the schools, universities, educational policy makers and technology experts. Working closely together with these coordinator teams, interdisciplinary advisory boards including educators, technology experts, scientists, and educational policy makers, on the level of federal states (on which decisions for the public school system are mostly made) are needed to identify the learning management systems, OER repositories, and further steps and activities of the campaign. Schools and teachereducating university institutes could start making the creation and evaluation of open educational resources are more central component of their everyday teaching and learning activities. Students could be involved to evaluate the difficulty level and other features of the created learning materials based on how they are perceived and mastered by large student groups. 